\title{
Pyogenic Granuloma: A Retrospective Analysis of Cases Treated Over a 10-Year
}

\author{
Mun Geun Koo, \\ Soo Hyang Lee, \\ So Eun Han \\ Department of Plastic and Reconstructive \\ Surgery, Inje University Ilsan Paik Hospital, \\ Inje University College of Medicine, Goyang, \\ Korea
}

No potential conflict of interest relevant to this article was reported.

\begin{abstract}
Background: Pyogenic granuloma (PG) is a benign vascular lesion of the mucosa and skin. Recent studies of the epidemiology of PG are rare. We aimed to retrospectively analyze characteristics of PG cases in South Korea.

Methods: We reviewed the medical records of 155 patients treated for PG between March 2005 and May 2014. The male-to-female ratio was 1:1.2 (70 males, 85 females). The mean age of patients was 35.3 years.

Results: A high occurrence was observed in the first and third decades in males, and the fourth to fifth decades in females. There was a statistically significant difference between genders according to age group $(p<0.05)$. The average lesion diameter was $0.84 \pm 0.46 \mathrm{~cm}$ (long axis). The most frequently involved site was the face $(n=47)$. Bleeding was the primary complication $(n=41)$. PG was mostly treated with excisional biopsy $(n=74)$. The recurrence rate was $7.7 \%(n=12)$.

Conclusion: We concluded that most common site of PG was the face, the age of female with PG is higher than previous studies, and finger is associated with trauma more than other sites. The most recent epidemiological information on PG of this study will support the treatment and diagnosis of $P G$ and future research objectives.
\end{abstract}

Keywords: Pyogenic granuloma / Analysis / Treatment

\section{INTRODUCTION}

Pyogenic granuloma $(\mathrm{PG})$ is an acquired, benign vascular tumor of the skin or mucous membrane. The term PG was first described in response to identification of an unidentified bacterium by Hartzell in 1904. However, PG is a misnomer as the condition is neither pyogenic nor granulomatous [1]. Histologically, maturated PG appears as clusters of hyperplastic capillaries separated by a lobule containing central feeder vessel. Therefore, it has also been called lobular capillary hemangioma to provide a more meaningful name [1]. PG presents as a solitary, red or purple smooth glistening papule that grows rapidly within days or weeks, and occurs frequently on the lips, gingiva, and fingers [2]. Bleed-

\section{Correspondence: Soo Hyang Lee}

Department of Plastic and Reconstructive Surgery, Inje University Ilsan Paik Hospital, Inje University College of Medicine, 170 Juhwa-ro, Goyang 10380, Korea

E-mail: shyanglee@naver.com

Received December 15, 2016 / Revised February 15, 2017 / Accepted February 15, 2017 ing and ulceration are common complications. PG can occur following minor trauma but also occurs spontaneously. The etiology of PG is unclear; it is considered a reactive tumor-like lesion arising by various stimuli, such as chronic low-grade irritation, traumatic injury, hormone effect, or drug-induced reaction [3,4]. PG occurs in all ages, but predominantly occurs in early childhood and the second decade of life in females, possibly due to vascular effects of hormonal change. Although PG sometimes self-resolves, many cases require treatment to control ulceration and bleeding. Numerous procedures are available for treatment, including surgical excision, curettage, cryotherapy, or laser ablation.

While there are many published studies of PG, most are limited to a particular topic, such as pregnant PG, oral cavity lesions, or specific case reports [5,6]. There are few recent studies describing the clinical features of PG. To meet this gap, we reviewed patients diagnosed with PG and who were treated a hospital in South Korea over a 10-year period. This study provides recent data of the

16 Copyright @ 2017 The Korean Cleft Palate-Craniofacial Association 
clinical characteristics, treatment, and recurrence rates of PG. The findings of this study will provide further support for the clinical management of PG.

\section{METHODS}

Investigation was performed targeting the patients diagnosed with the PG from March 2005 to May 2014 in Ilsan Paik Hospital, Go-yang city, South Korea. The analysis was conducted retrospectively by medical record.

The following inclusion criteria were used: (1) the patient was diagnosed with PG or lobular capillary hemangioma, (2) followup period was more than 3 months, (3) biopsy must be done and the result should come out with PG. Patients were excluded if (1) the PG was diagnosed only physical exam, (2) biopsy result was revealed with other malignancy or mixed, (3) follow-up loss.

Data collected include age, gender, location, etiology, size of lesion, symptoms, treatment method, and recurrence. Age was divided into 10 year age bands. Topographical location was subdivided into subgroups as follows; scalp, face, lip \& oral cavity, neck, trunk, finger, upper extremity, and lower extremity. Lip \& oral cavity and finger were distinguished form facial area and upper extremity respectively because these sites were known as a common outbreak area of PG.

Data were analyzed using PASW ver. 18.0 (SPSS Inc., Chicago, IL, USA). Comparisons were made using the t-test and correlation analysis. Significance was set at a $p$-value $<0.05$.

\section{RESULTS}

The searches identified 258 patients diagnosed PG. By matching the inclusion criteria, 103 patients were excluded due to be diagnosed only physical examination or other malignancy, or follow-up loss. The remaining 155 patients were included the final analysis.

Among the 155 patients, 70 were men (45\%) and 85 women (55\%); a male-to-female ratio of 1:1.2. The mean age was 35.3 years (range, 0-82 years), with a similar distribution in the first to fifth decades of life. Between genders, the prevalence of PG by age groups was significantly different $(p<0.05)$ (Fig. 1).
Of the 155 cases of PG, 47 lesions (30\%) were facial and 35 lesions were on fingers (23\%). Scalp was the third most affected site (Table 1) The face was the most commonly affected site (12 patients, 57\%) during the first decade, whereas, the finger the most commonly affected site during the fifth decade.

Characteristics of the PG according to location and age subgroup were summarized in Tables 2 and 3. The average lesion diameter was $0.84 \pm 0.46 \mathrm{~cm}$ (long axis). There was no statistically significant difference in lesion diameter between men and women

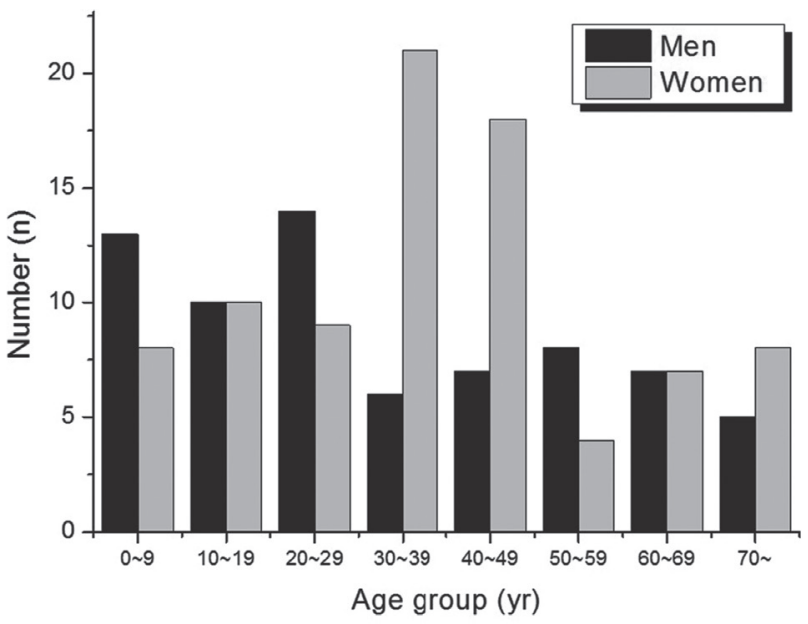

Fig. 1. Distribution of pyogenic granuloma by age and sex.

Table 1. Distribution of pyogenic granuloma according to anatomical site

\begin{tabular}{lccc|} 
Location & $\begin{array}{c}\text { No. of } \\
\text { total patients }\end{array}$ & $\begin{array}{c}\text { No. of } \\
\text { male }\end{array}$ & $\begin{array}{c}\text { No. of } \\
\text { female }\end{array}$ \\
\hline Scalp & 19 & 11 & 8 \\
\hline Face (total) & 47 & 23 & 24 \\
\hline Cheek & 14 & 6 & 8 \\
\hline Forehead & 8 & 4 & 4 \\
\hline Nose & 8 & 4 & 4 \\
\hline Eyebrow & 5 & 1 & 4 \\
\hline Eyelid & 5 & 3 & 2 \\
\hline Chin & 4 & 4 & 0 \\
\hline Nasal mucosa & 2 & 0 & 2 \\
\hline Conjunctiva & 1 & 1 & 0 \\
\hline Neck & 5 & 3 & 2 \\
\hline Lip and oral cavity & 15 & 5 & 10 \\
\hline Trunk & 9 & 4 & 5 \\
\hline Upper extremity & 13 & 5 & 8 \\
\hline Finger & 35 & 13 & 22 \\
\hline Lower extremity & 12 & 6 & 6 \\
\hline & & &
\end{tabular}


Table 2. Characteristics of the pyogenic granuloma based on location

\begin{tabular}{|c|c|c|c|c|c|c|c|c|c|}
\hline Character & Scalp (\%) & Face (\%) & Neck (\%) & $\begin{array}{l}\text { Lip \& oral } \\
\text { cavity (\%) }\end{array}$ & Trunk (\%) & Finger (\%) & $\begin{array}{c}\text { Upper } \\
\text { extremity (\%) }\end{array}$ & $\begin{array}{c}\text { Lower } \\
\text { extremity (\%) }\end{array}$ & Total \\
\hline \multicolumn{10}{|l|}{ Symptom } \\
\hline Asymptomatic & $11(10.8)$ & 31 (30.4) & $4(3.9)$ & $10(9.8)$ & $6(5.9)$ & $23(22.5)$ & $9(8.8)$ & $8(7.8)$ & 102 \\
\hline Bleeding & $6(14.6)$ & $13(31.7)$ & $1(2.4)$ & $4(9.8)$ & $2(4.9)$ & $11(26.8)$ & $3(7.3)$ & $1(2.4)$ & 41 \\
\hline Pain & $2(16.7)$ & $3(25.0)$ & 0 & $1(8.3)$ & $1(8.3)$ & $1(8.3)$ & $1(8.3)$ & $3(25.0)$ & 12 \\
\hline \multicolumn{10}{|l|}{ Etiology } \\
\hline Trauma & $4(18.2)$ & $6(27.3)$ & $1(4.5)$ & 0 & 0 & 8 (36.4) & 0 & $3(13.6)$ & 22 \\
\hline Irritation & $1(7.7)$ & $10(76.9)$ & 0 & $2(15.4)$ & 0 & 0 & 0 & 0 & 13 \\
\hline Unknown & $14(11.7)$ & $31(25.8)$ & $4(3.3)$ & $13(10.8)$ & $9(7.5)$ & 27 (22.5) & $13(10.8)$ & $9(7.5)$ & 120 \\
\hline \multicolumn{10}{|l|}{ Treatment } \\
\hline Excision & $9(12.2)$ & 18 (24.3) & $4(5.4)$ & $7(9.5)$ & $4(5.4)$ & $20(27.0)$ & $8(10.8)$ & $4(5.4)$ & 74 \\
\hline Laser ablation & $7(11.9)$ & $23(39.0)$ & $1(1.7)$ & $5(8.5)$ & $3(5.1)$ & $10(16.9)$ & $4(6.8)$ & $6(10.2)$ & 59 \\
\hline Electrodessication & $1(14.3)$ & $1(14.3)$ & 0 & $1(14.3)$ & $1(14.3)$ & $3(42.9)$ & 0 & 0 & 7 \\
\hline Observation & 0 & $5(38.5)$ & 0 & $2(15.4)$ & $1(7.7)$ & $2(15.4)$ & $1(7.7)$ & $2(15.4)$ & 13 \\
\hline Recurrence & 0 & $4(33.3)$ & 0 & $1(8.3)$ & 1 (8.3) & 4 (33.3) & $2(16.7)$ & 0 & 12 \\
\hline
\end{tabular}

Table 3. Characteristics of the pyogenic granuloma based on age subgroup

\begin{tabular}{|c|c|c|c|c|c|c|c|c|c|}
\hline Character & $0-9(\%)$ & $10-19(\%)$ & $20-29(\%)$ & $30-39(\%)$ & $40-49(\%)$ & $50-59(\%)$ & $60-69(\%)$ & $\leq 70(\%)$ & Total \\
\hline \multicolumn{10}{|l|}{ Symptom } \\
\hline Asymptomatic & $12(11.8)$ & $18(17.6)$ & $14(13.7)$ & $13(12.7)$ & $18(17.6)$ & $5(4.9)$ & $12(11.8)$ & $10(9.8)$ & 102 \\
\hline Bleeding & $8(19.5)$ & $2(4.9)$ & $6(14.6)$ & $10(24.4)$ & $6(14.6)$ & $5(12.2)$ & $2(4.9)$ & $2(4.9)$ & 41 \\
\hline Pain & $1(8.3)$ & 0 & $3(25.0)$ & $4(33.3)$ & $1(8.3)$ & $2(16.7)$ & 0 & $1(8.3)$ & 12 \\
\hline \multicolumn{10}{|l|}{ Etiology } \\
\hline Trauma & $2(9.1)$ & $3(13.6)$ & $1(4.5)$ & $7(31.8)$ & $6(27.3)$ & 0 & $2(9.1)$ & $1(4.5)$ & 22 \\
\hline Irritation & $3(23.1)$ & $2(15.4)$ & $3(23.1)$ & $1(7.7)$ & $1(7.7)$ & 0 & $1(7.7)$ & $2(15.4)$ & 13 \\
\hline Unknown & 16 (13.3) & $15(12.5)$ & $19(15.8)$ & $19(15.8)$ & $18(15.0)$ & $12(10.0)$ & $11(9.2)$ & $10(8.3)$ & 120 \\
\hline \multicolumn{10}{|l|}{ Treatment } \\
\hline Excision & $7(9.5)$ & $10(13.5)$ & $13(17.6)$ & $12(16.2)$ & 14 (18.9) & $6(8.1)$ & $3(4.1)$ & $9(12.2)$ & 74 \\
\hline Laser ablation & $11(18.6)$ & $8(13.6)$ & $9(15.3)$ & $10(16.9)$ & $7(11.9)$ & $5(8.5)$ & $8(13.6)$ & $1(1.7)$ & 59 \\
\hline Electrodessication & $1(14.3)$ & $1(14.3)$ & $1(14.3)$ & $1(14.3)$ & $1(14.3)$ & $1(14.3)$ & 0 & $1(14.3)$ & 7 \\
\hline Observation & $2(13.3)$ & $1(6.7)$ & 0 & $4(26.7)$ & $3(20.0)$ & 0 & $3(20.0)$ & $2(13.3)$ & 15 \\
\hline Recurrence & $1(8.3)$ & $2(16.7)$ & 0 & $3(25.0)$ & $2(16.7)$ & $2(16.7)$ & $1(8.3)$ & $1(8.3)$ & 12 \\
\hline
\end{tabular}

$(p>0.05)$. The majority of patients had no symptoms (102 patients, $66 \%$ ). Bleeding was the most common complication (41 patients, $26 \%$ ) and pain was the second (12 patients, $8 \%$ ). Twenty-two patients had a history of trauma at the site of the lesion (14\%) and 13 patients had a history of irritation at the site of the lesion (8\%). Unknown etiology was present for the majority of patients (120 patients, 78\%).

Complete excision was performed on 74 patients (48\%). Other treatments were: laser ablation (59 patients, 38\%), electrodessication (seven patients, $5 \%$ ), and observation (15 patients, 10\%). Of the observed patients, seven patients were resolved by medication, seven patients were resolved by excisional biopsy, and one patient underwent cauterization. The mean follow up period was 39.1 months (range, 3-112 months). There were 12 recurrences among patients (7.7\%); six of these recurrences were treated by laser ablation, four patients were treated by surgery, and others were treated 
through observation and medication.

\section{DISCUSSION}

PG, also known as lobular capillary hemangioma, is a benign proliferative vascular tumor which most commonly affects the skin or mucosa of children [1]. The mean age of patients in this study was 35.2 years. Some studies have shown that mean age ranges from 30 to 40 years [7,8]. Of the 155 patients in this study, 70 were men, and 85 were women, a male-female ratio of 1:1.2. We divided age into 10-year age bands in order to investigate age-specific incidence. In males, 14 patients (20\%) and 13 patients (19\%) were diagnosed in the first and third decades, respectively. In women, 21 patients $(25 \%)$ and 18 patients (21\%) were diagnosed in the fourth and fifth decades, respectively. There was no association of incidence with decades of life. However, the peak incidence was seen in men aged $<30$ years ( 37 patients, $53 \%$ ), and the fourth and fifth decades of life in women (39 patients, 46\%). A previous study reported that the second, third and fourth decades of life were associated with increased incidence of PG in women $[9,10]$. Pregnancy has previously been reported as a causative factor for PG [6]. We suggest thought that the increase of pregnancy age shifted the incidence of PG in women. Further research is required to investigate the relationship between age at pregnancy and the incidence of PG.

PG can present anywhere on the body. It commonly affects the cheek, lip and oral mucosa, and finger [1,7], but has also been reported to affect the liver, blood vessels, and central nervous system $[3,4]$. In our study, the face, excluding scalp, lip and oral cavity, were the most commonly affected sites in both genders. Other studies have also reported that the head and neck are the most commonly affected sites [1,7]. Of face lesions, the cheek (14 patients) was the most common site, followed by forehead (8 patients). For the first time we have found that the scalp can account for a large percentage of PG lesions (19 patients). Mucosal PG has been reported as common in females, more than twice the incidence in males [8]. We also founded that the incidence of mucosal PG in women was twice that in males, although there was no statistically significant difference between genders.
The average diameter of a PG lesion was $0.84( \pm 0.46 \mathrm{~cm})$ in this study. Previous studies have shown that the average diameter of PG lesions is approximately $0.65 \mathrm{~cm}$ [1]. In our study, although the largest diameter was $3.5 \mathrm{~cm}$, most cases presented with a lesion smaller than $1 \mathrm{~cm}$ in diameter (132 patients, $85.2 \%$ ).

Minor trauma or chronic irritation can cause PG [11]. PG may also arise by various stimuli such as hormone effect or drug-induced reaction $[6,8]$. Specifically, the finger is considered as the major site because it is the site of consistent exposure to minor trauma [12]. However, a recent study observed that only $7 \%$ of patients had a history of trauma [1]. In our study, only a small percentage of patients (22 patients, 14.2\%) had a history of trauma preceding lesion onset. In finger lesions, many more patients (22.9\%) were related to trauma. This finding reemphasizes the correlation between trauma and PG finger lesions.

Of the 155 patients in this study, 12 relapsed following laser treatment (6 patients), excision (4 patients), and observation (2 patients). In electrodessication, there were no recurrences. However, this was not statistical significant due to the small number of cases.

Because this study was carried out in a retrospective study, it was difficult to clearly explain the relationship between occurrence location and treatment modalities. In addition, because it depended only on chart analysis, it is also difficult to get all the information about characteristics of the patients. Therefore, wellplanned with adequate number of cases prospective studies are necessary to reach on the accurate results of PG.

This study has produced three important results. Firstly, that the most common site of PG was the face. On the facial area, the cheek was the most common site. Secondly, the age of females with PG is higher than reported in previous studies. This may be related to an increased gestational age. Thirdly, PG occurring in the finger is associated with trauma more than other affected sites. Through this study, we have reported the most recent epidemiological information on PG which will be helpful in treatment and diagnosis of PG and for considering future research objectives.

\section{REFERENCES}

1. Patrice SJ, Wiss K, Mulliken JB. Pyogenic granuloma (lobular capil- 
lary hemangioma): a clinicopathologic study of 178 cases. Pediatr Dermatol 1991;8:267-76.

2. Fortna RR, Junkins-Hopkins JM. A case of lobular capillary hemangioma (pyogenic granuloma), localized to the subcutaneous tissue, and a review of the literature. Am J Dermatopathol 2007;29:408-11.

3. Abaalkhail F, Castonguay M, Driman DK, Parfitt J, Marotta P. Lobular capillary hemangioma of the liver. Hepatobiliary Pancreat Dis Int 2009;8:323-5.

4. Abe M, Misago N, Tanaka S, Masuoka J, Tabuchi K. Capillary hemangioma of the central nervous system: a comparative study with lobular capillary hemangioma of the skin. Acta Neuropathol 2005;109:151-8.

5. Cooper PH, McAllister HA, Helwig EB. Intravenous pyogenic granuloma: a study of 18 cases. Am J Surg Pathol 1979;3:221-8.

6. Henry F, Quatresooz P, Valverde-Lopez JC, Pierard GE. Blood vessel changes during pregnancy: a review. Am J Clin Dermatol 2006;7:65-9.

7. Akamatsu T, Hanai U, Kobayashi M, Miyasaka M. Pyogenic granulo- ma: a retrospective 10-year analysis of 82 cases. Tokai J Exp Clin Med 2015;40:110-4.

8. Harris MN, Desai R, Chuang TY, Hood AF, Mirowski GW. Lobular capillary hemangiomas: an epidemiologic report, with emphasis on cutaneous lesions. J Am Acad Dermatol 2000;42:1012-6.

9. Gordon-Nunez MA, de Vasconcelos Carvalho M, Benevenuto TG, Lopes MF, Silva LM, Galvao HC. Oral pyogenic granuloma: a retrospective analysis of 293 cases in a Brazilian population. J Oral Maxillofac Surg 2010;68:2185-8.

10. Saravana GH. Oral pyogenic granuloma: a review of 137 cases. Br J Oral Maxillofac Surg 2009;47:318-9.

11. Kerr DA. Granuloma pyogenicum. Oral Surg Oral Med Oral Pathol 1951;4:158-76.

12. Nkanza NK, Hutt MS. Pyogenic granuloma: a study of 181 cases from Malawi. East Afr Med J 1981;58:318-23. 